\title{
Thermal imaging and planimetry evaluation of the results of chronic wounds treatment with hyperbaric oxygen therapy
}

\author{
Justyna Gliki,2,A,B,D, Armand Cholewka ${ }^{3, B-D}$, Agata Stanek ${ }^{4, C-E}$, Beata Englisz, ${ }^{3, B}$, Karolina Sieron ${ }^{5, C}$, \\ Karolina Mikuś-Zagórska ${ }^{1, A-C}$, Grzegorz Knefel ${ }^{1, B, C}$, Mariusz Nowak ${ }^{1, C, F}$, Marek Kawecki ${ }^{1,6, A, E, F}$ \\ ${ }^{1}$ Dr Stanisław Sakiel Centre for Burns Treatment, Siemianowice Śląskie, Poland \\ 2 Department of Chronic Wounds Management Organization, School of Health Sciences in Katowice, Medical University of Silesia, Poland \\ ${ }^{3}$ August Chełkowski Institute of Physics, University of Silesia, Katowice, Poland \\ ${ }^{4}$ School of Medicine with the Division of Dentistry in Zabrze, Department and Clinic of Internal Diseases, Angiology and Physical Medicine in Bytom, \\ Medical University of Silesia, Poland \\ ${ }^{5}$ Chair of Physiotherapy, Department of Physical Medicine, School of Health Sciences in Katowice, Medical University of Silesia, Poland \\ ${ }^{6}$ Department of Health Sciences, Technical-Humanistic Academy, Bielsko-Biała, Poland \\ A - research concept and design; B - collection and/or assembly of data; $C$ - data analysis and interpretation; \\ $\mathrm{D}$ - writing the article; $\mathrm{E}$ - critical revision of the article; $\mathrm{F}$ - final approval of the article
}

Address for correspondence

Armand Cholewka

E-mail: armand.cholewka@gmail.com

Funding sources

None declared

Conflict of interest

None declared

Received on July 11, 2017

Reviewed on May 9, 2018

Accepted on June 15, 2018

Published online on September 21, 2018

Cite as

Glik J, Cholewka A, Stanek A, et al. Thermal imaging

and planimetry evaluation of the results of chronic wounds

treatment with hyperbaric oxygen therapy. Adv Clin Exp Med

2019:28(2):229-236. doi:10.17219/acem/92304

DOI

$10.17219 /$ acem/92304

Copyright

Copyright by Author(s)

This is an article distributed under the terms of the

Creative Commons Attribution Non-Commercial License

(http://creativecommons.org/licenses/by-nc-nd/4.0/)

\section{Abstract}

Background. One of the methods to treat chronic wounds is the use of hyperbaric oxygen (HBO). Objective measurement of the wound surface is an important element in the process of monitoring and predicting the progress of treatment.

Objectives. The aim of the study was to evaluate the effect of hyperbaric oxygen therapy (HBOT) on ulcer wound healing in patients with chronic venous insufficiency ulcers and diabetic foot syndrome using thermal imaging and computerized planimetry.

Material and methods. During a 3-year period, 284 digital computer planimetry measurements were gathered from 142 patients treated for leg ulcers caused by chronic venous insufficiency and ulcers from diabetic foot syndrome at HBOT Unit of the Dr Stanisław Sakiel Centre for Burns Treatment in Siemianowice Ślaskie (Poland). Each patient took 30 HBOT sessions using a Haux multiplace HBO chamber at a pressure of 2.5 atmospheres absolute (ATA). The results of the treatment were monitored using thermovision and computerassisted planimetry measurements performed before and after HBOT.

Results. Both groups of patients exhibited a reduction in the surface and perimeter of the wound after HBOT. The treatment effects were also confirmed with thermal imaging. The areas calculated from thermal imaging and planimetry are different but correlated.

Conclusions. It seems that a combination of thermal imaging and planimetry may enhance the diagnosis as well as provide the physician with more information about therapy effects.

Key words: chronic wounds, thermal imaging, planimetry, hyperbaric oxygen therapy 


\section{Introduction}

Numerous studies have focused on the treatment of chronic wounds and, in particular, their objective assessment, as well as simple, effective and objective monitoring of the healing process, with emphasis on the possibility of storing data for subsequent comparison. Hyperbaric oxygen therapy (HBOT) is a non-invasive method that includes breathing pure oxygen under increased pressure conditions, which facilitates the healing of chronic wounds. ${ }^{1}$ Sometimes it is the only therapeutic method which allows for avoiding limb amputation after all other available treatment methods have failed. ${ }^{2}$ There are numerous factors indicating wound healing, such as reduction of wound exudate and bacterial load, speed of granulation tissue formation, rapidity of epithelialization, etc. ${ }^{3}$ However, the assessment of wound healing is based in most of the cases only on clinical signs, manual measurements or photographic documentation, which are more or less objective and can cause errors in the assessment of healing process dynamics. Making a distinction between a healing and a non-healing wound allows the physician to decide whether to continue the selected therapy or to use alternative methods of treatment. Measurements using a ruler or a transparent film placed over the wound to trace its contours can be used to assess the ulceration surface. Despite being suitable for small area wounds with regular shapes, these methods have many disadvantages. ${ }^{4-6}$ Digital computer planimetry allows for measuring of wounds on digital images by tracing their contours using specialized computer software. ${ }^{7,8}$ The wound measurement is performed automatically. The digital system provides recording, processing and analyses of the images obtained. The reference scale used in the photograph guarantees the accuracy of the measurements. ${ }^{8}$

Methods like planimetry and oximetry are used in the qualification of a patient for HBOT and in the evaluation of the therapy effects. However, a non-invasive, easy to perform and quick method of evaluating the treatment effects as well as of the diagnosis of the patient's condition is still needed. Such method might be thermovision, which is used more and more widely in medicine. ${ }^{9}$ That is why the aim of presented work is to determine and compare the diagnostic value of computer planimetry and thermal imaging of patients treated with HBOT.

\section{Material and methods}

Inclusion criteria to the study population were as follows: - presenting with 2 selected types of chronic wounds: leg ulcers due to chronic venous insufficiency in the phase $\mathrm{C} 6$ active venous ulcers according of Clinical-Etiology-Anatomy-Pathophysiology classification (CEAP) (Group A) and the diabetic foot stage 1 and 2 ulcers according to Wagner Classification (Group B);

- signed informed consent for participation in the objective (planimetric) assessment of wound surface and perimeter before and after $\mathrm{HBOT}$;

- participation in 30 HBOT sessions.

According to the general HBOT contraindications, only patients without any respiratory obstruction or other conditions such as pneumothorax, active neoplastic process, claustrophobia, or psychiatric disease in medical history were included in HBOT group.

All patients from both groups were referred for $\mathrm{HBOT}$ after ineffective conservative treatment: compression therapy, targeted antibiotic treatment, local use of antiseptics, phlebotropic drugs, diabetes medications, and special dressings. Before the beginning of treatment in the hyperbaric chamber, all patients were prepared and qualified for HBOT by their physicians-in-charge or were referred to the Hyperbaric Oxygen Therapy Unit at the Dr Stanisław Sakiel Centre for Burns Treatment in Siemianowice Sląskie (Poland) after hospitalization at internal medicine, surgery or dermatology departments, or after outpatient treatment. The patient's qualification for HBOT was finally approved by a multidisciplinary medical council. Apart from the medical history, physical examination and photographic documentation, planimetric measurements and partial oxygen concentration measurements in the skin around the wound were performed using transcutaneous oximetry. Each patient qualified for HBOT was provided with local and general treatment at the Outpatient Unit of the Centre for Burns Treatment. If pain symptoms occurred, all patients took nonsteroidal anti-inflammatory drugs. A coexisting disease stabilization standard was applied in all patients. In patients with diabetes, glucose levels were stabilized before start of HBOT and maintained during the entire treatment period. Each patient qualified for HBOT received standard local treatment in accordance with the guidelines of Polish Wound Treatment Society. ${ }^{10,11}$ Before the start of the therapy, each patient was informed about the principles of safety, as well as about the objects and substances which could not be used during treatment in the hyperbaric chamber. All data was encoded to prevent identification of patients.

The study was approved by the local research ethics committee and was carried out in accordance with the principles set forth in the Declaration of Helsinki.

The study material is based on 142 patients treated in the Hyperbaric Oxygenation Ward of the Centre for Burns Treatment in Siemianowice Śląskie between 2009 and 2012. The study population characteristics are shown in Table 1.

No complications were observed during HBOT in any patients. From the total number of 432 patients, 290 were 
Table 1. Characteristics of studied patient population

\begin{tabular}{|l|c|c|c|}
\multicolumn{1}{|c|}{ Group } & Number of patients & Males & Females \\
\hline $\begin{array}{l}\text { A - with venous ulcers due } \\
\text { to chronic venous insufficiency }\end{array}$ & $98(69 \%)$ & $39(40 \%)$ & $59(60 \%)$ \\
\hline B - with diabetic foot ulcer & $44(31 \%)$ & $22(50 \%)$ & Age \\
\hline
\end{tabular}

excluded from the research. Among them, 227 (52.5\%) patients were excluded due to incompatibility with diagnosis inclusion criteria; 25 patients $(5.8 \%)$ were excluded as they withdrew from the treatment before completing the obligatory 30 HBOT sessions, and 38 patients $(8.8 \%)$ were excluded due to the absence of objective examination process (patients with circular wounds).

\section{Hyperbaric oxygen application}

All patients underwent 30 sessions of HBOT in a multiplace hyperbaric oxygen (HBO) chamber (Haux-Life Support $\mathrm{GmbH}$, Karlsbad-Ittersbach, Germany). Sessions were performed every $24 \mathrm{~h}, 5$ times per week. During 90-minute sessions in a $\mathrm{HBO}$ chamber, patients were breathing pure oxygen for $60 \mathrm{~min}$ (under pressure of 2.5 atmospheres absolute - ATA) with 25 -minute air breaks.

\section{Wound evaluation}

Each ulcer was marked initially by tracing its borders before and after HBOT, and was documented by digital pictures. The pictures were then analyzed by computerized wound planimetry.

Planimetric system IRIS ${ }^{\circledR}$ (Medicom, Wrocław, Poland), used for planimetric examination, enabled the measurement of the wound size (surface and perimeter) by specialized computer software (images with regions of interest and parameters can be seen in Fig. 1A and B. Additionally, once a week photographic documentation of all wounds was performed and clinical wound evaluation data was recorded. Both planimetric measurements and clinical evaluation records were used for the analysis of results.

\section{Thermal imaging}

The distribution of the skin surface temperature was monitored with the use of a Thermovision Camera E60 (Flir Systems, Täby, Sweden) calibrated by black body. The thermograms of the chosen regions of interest were performed before and immediately after HBOT in a special room outside the chamber. There were 30 cases studied by thermal imaging. Thermal imaging was performed according to Glamorgan Protocol and took into account the standardization of infrared thermal imaging. ${ }^{12,13}$

Statistical analysis was done using STATISTICA v. 10.1 (StatSoft Inc., Tulsa, USA) and the data was analyzed

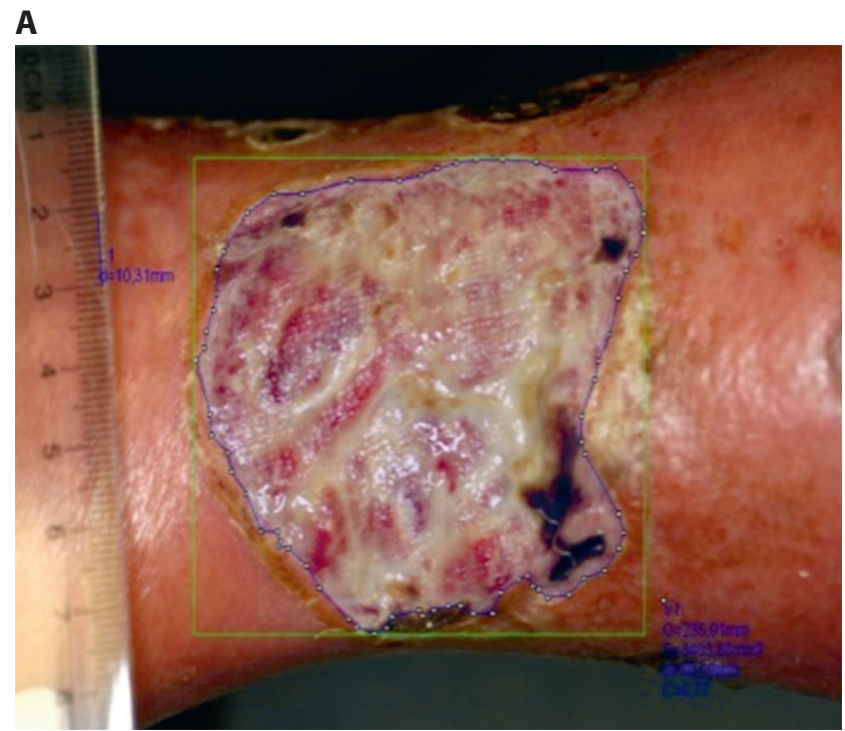

B

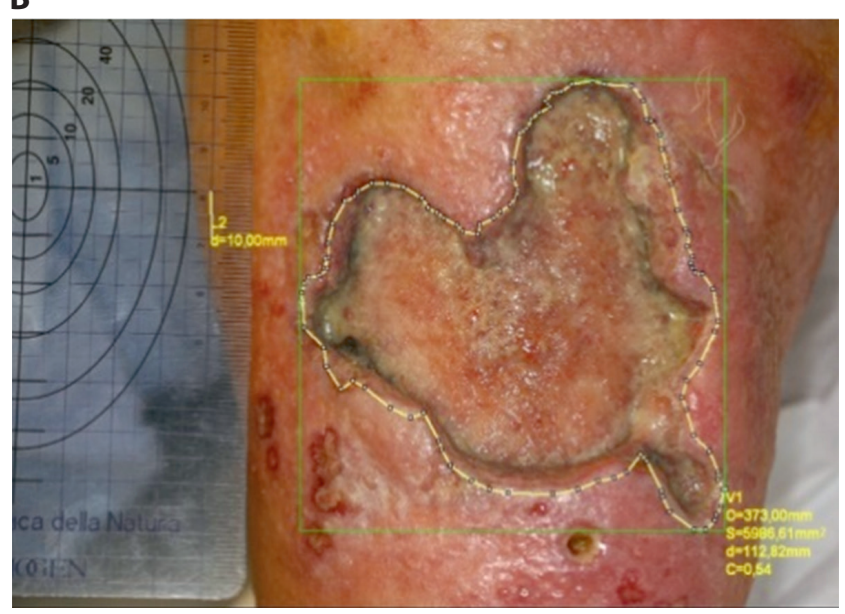

Fig. 1. Digital computerized wound planimetry

based on the calculation of median values and the range for collected data, including demography/age of treatment group. In order to study the impact of one variable on another, Spearman's rank correlation coefficient was determined. Moreover, paired-sample t-test for normal values distribution and Mann-Whitney U test or Wilcoxon test were used when data was characterized by abnormal distribution. The normality of distribution was checked by Levene's test. When more than 2 groups were compared, the analysis of variance (ANOVA) test was used. Differences with a p-value $<0.05$ were considered significant. 


\section{Results}

\section{Analysis of clinical results of treatment in both groups after hyperbaric oxygen therapy}

In 16 patients (16.32\%) from Group A, complete wound healing was achieved. In 82 patients $(83.67 \%)$, wound reduction was observed and they were qualified for further treatment with split-thickness skin grafts.

In 9 patients (20.45\%) from Group B, complete wound healing was achieved. In 35 patients (79.55\%), wound reduction was observed and they were qualified for further treatment with split-thickness skin grafts.

\section{Planimetry measurements results}

In Group A, the average wound perimeter after HBOT was $128.80 \pm 122.81 \mathrm{~mm}$, which was significantly lower than the average wound perimeter $171.70 \pm 123.76 \mathrm{~mm}$ ( $\mathrm{p}=0.001$ ) before HBOT (Fig. 2).

The average wound surface area after HBOT was $954.90 \pm 1349.97 \mathrm{~mm}^{2}$, which was found again to be significantly lower than the average wound surface area of 1636.60 $\pm 2101.22 \mathrm{~mm}^{2}$ ( $\mathrm{p}=0.0005$ ) before HBOT (Fig. 3).

In Group B, we observed that the average wound perimeter was $75.20 \pm 51.23 \mathrm{~mm}$ after HBOT and it was significantly lower than the average wound perimeter of $99.00 \pm 66.06 \mathrm{~mm}(\mathrm{p}=0.0101)$ before HBOT (Fig. 4).

The average wound surface area after HBOT was 303.40 $\pm 288.04 \mathrm{~mm}^{2}$ and it was significantly lower than the average wound surface of $663.80 \pm 745.38 \mathrm{~mm}^{2}$ before HBOT $(\mathrm{p}=0.011)($ Fig. 5).

\section{Thermal imaging results}

The thermal images for representative patients (the images were chosen for the best illustration of the studied problem) suffering from venous crural ulceration were performed before (a) and after (b) HBOT session, with the collected temperature parameters derived from chosen areas, are presented in Fig. $6 .{ }^{14}$

The region of interest (part of the lower extremities) was divided into 3 parts (area 1 (AR01) - ulceration, area 2 (AR02) - closer area above the wound, area 3 (AR03) - further areas below the wound). It is clearly visible that the skin temperature changes due to HBOT. However, to see the problem more clearly, some statistical analysis had to be performed. The mean temperature changes due to HBOT are presented in Fig. 7. Despite no statistical significance between the mean temperature of the whole studied region of interest before as well as after hyperbaric oxygenation $(p>0.05)$, it can be seen that the temperature range of these areas was less differentiated after HBOT than before HBOT. However, the situation changed when the temperature difference

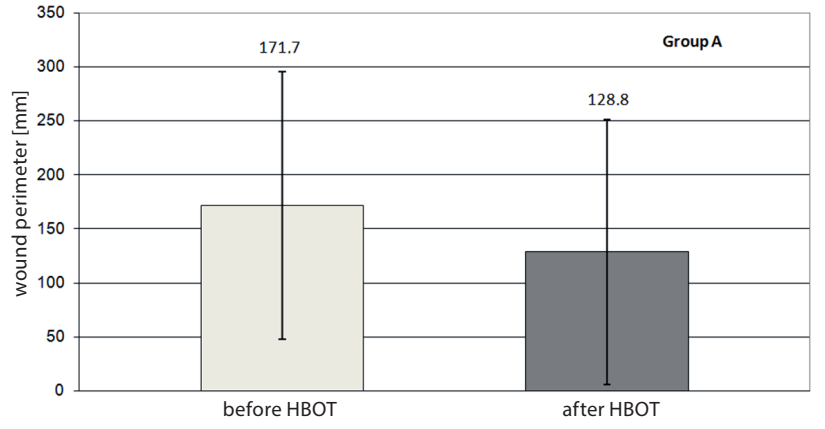

Fig. 2. Comparison of average wound perimeter before and after hyperbaric oxygen therapy (HBOT) in Group A

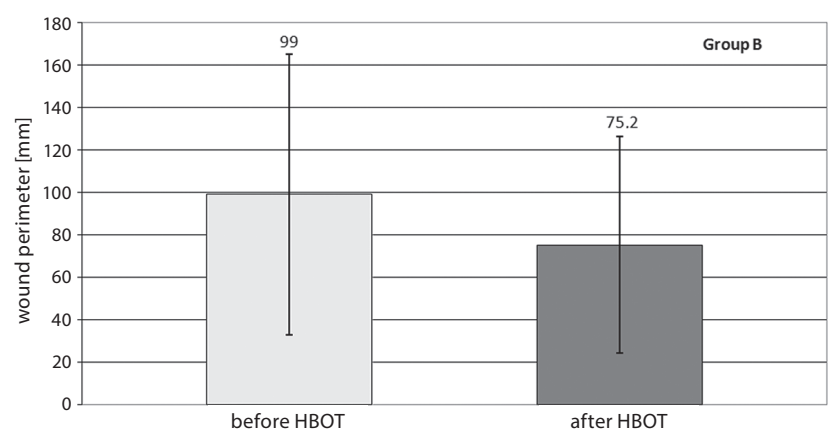

Fig. 3. Comparison of average wound perimeter before and after hyperbaric oxygen therapy (HBOT) in Group B

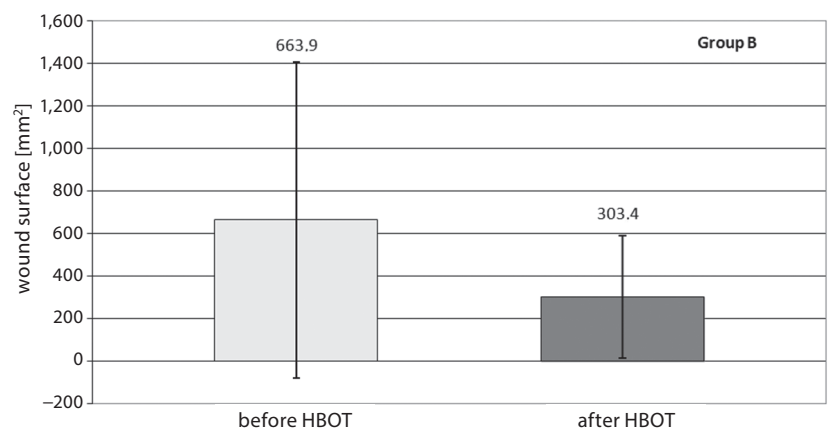

Fig. 4. Comparison of average wound surface before and after hyperbaric oxygen therapy (HBOT) in Group B

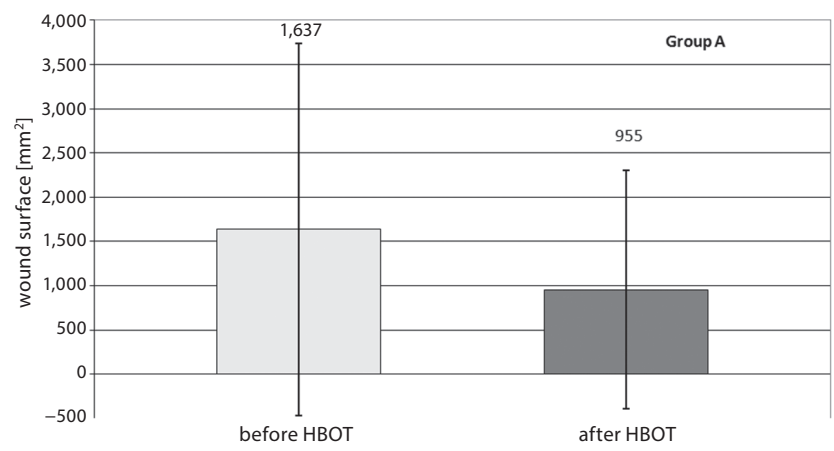

Fig. 5. Comparison of average wound surface before and after hyperbaric oxygen therapy (HBOT) in Group A 

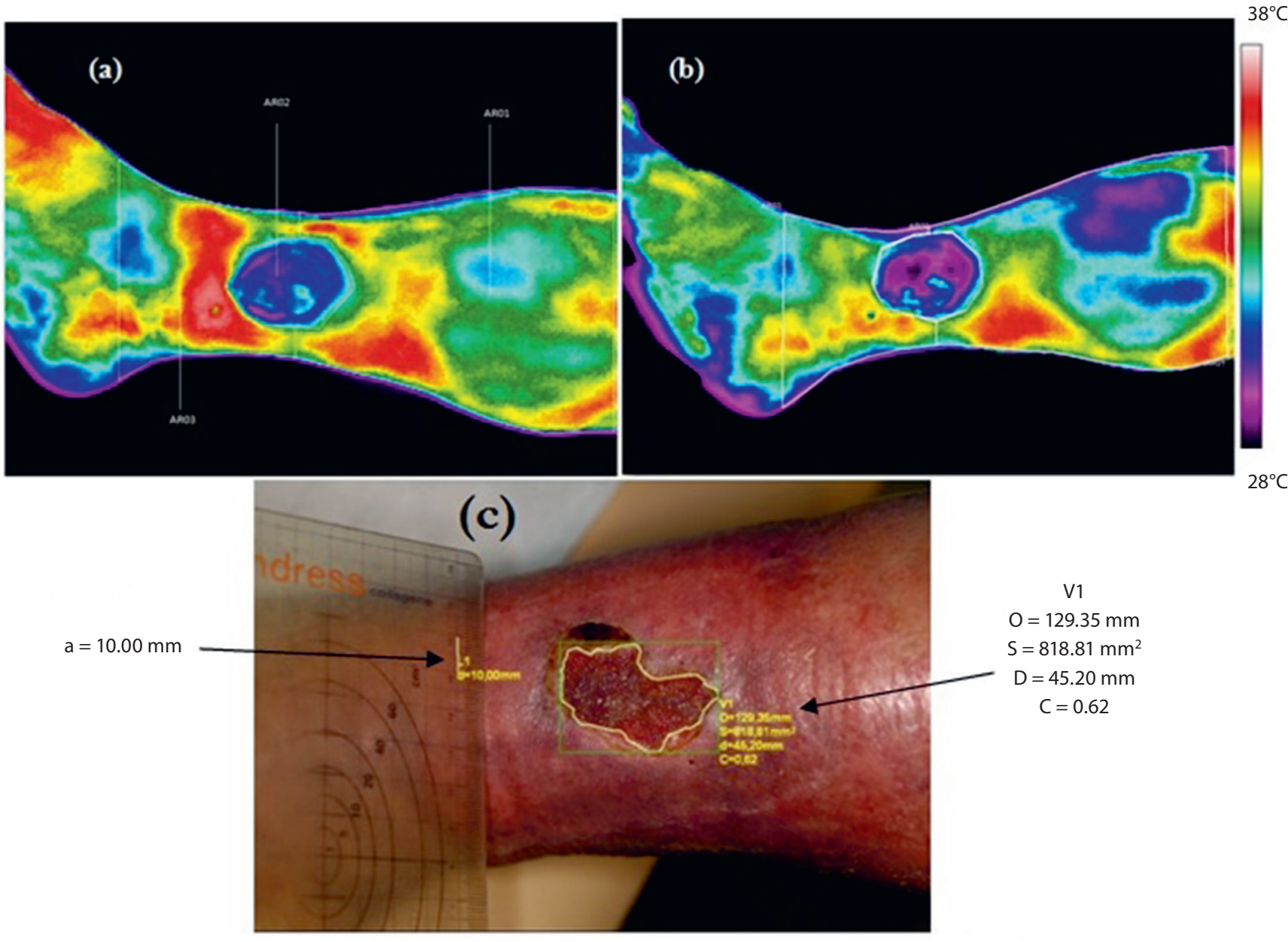

\begin{tabular}{|l|c|c|c|c|}
\hline \multicolumn{1}{|c|}{ Area } & $\mathrm{T}_{\text {mean }}$ before HBOT $\left[{ }^{\circ} \mathrm{C}\right]$ & $\mathrm{T}_{\text {mean }}$ after HBOT $\left[{ }^{\circ} \mathrm{C}\right]$ & Area $\left[\mathrm{mm}^{2}\right]$ & $\begin{array}{c}\text { Number of pixels } \\
\text { counted from thermal } \\
\text { imaging }\end{array}$ \\
\hline AR01 & 33.0 & 31.6 & - & - \\
\hline AR02 & 31.3 & 30.5 & 818.8 & $2,330.0$ \\
\hline AR03 & 33.2 & 31.8 & - & - \\
\hline
\end{tabular}

Fig. 6. The thermal image of representative patients suffering from venous chronic ulceration, performed before (a) and after (b) the hyperbaric oxygen therapy (HBOT) session, planimetry image (c) and results of temperature and planimetry parameters obtained from chosen areas ${ }^{14}$

between AR01 and AR02 before and after HBOT was considered. A deeper analysis showed that the decrease of the mean temperature difference between AR01 and AR02 (marked in Fig. 7 with an arrow) was nearly 3 times smaller: $\Delta \mathrm{T}=0.9$ observed before hyperbaric oxygenation in comparison to $\Delta \mathrm{T}=0.3$ observed after hyperbaric oxygenation. ${ }^{14}$ The difference was statistically significant $(\mathrm{p}=0.031)$.

Similar tendencies can also be observed in other thermal imaging results (Fig. 8). The differences between the areas derived from planimetry and from thermal images as a number of pixels (Fig. 6) are determined by 2 different ways of analysis - structural in the case of planimetry and metabolical in thermovision. Connecting these 2 imaging techniques may provide additional information in diagnosis, as well as in the evaluation of therapy effects.

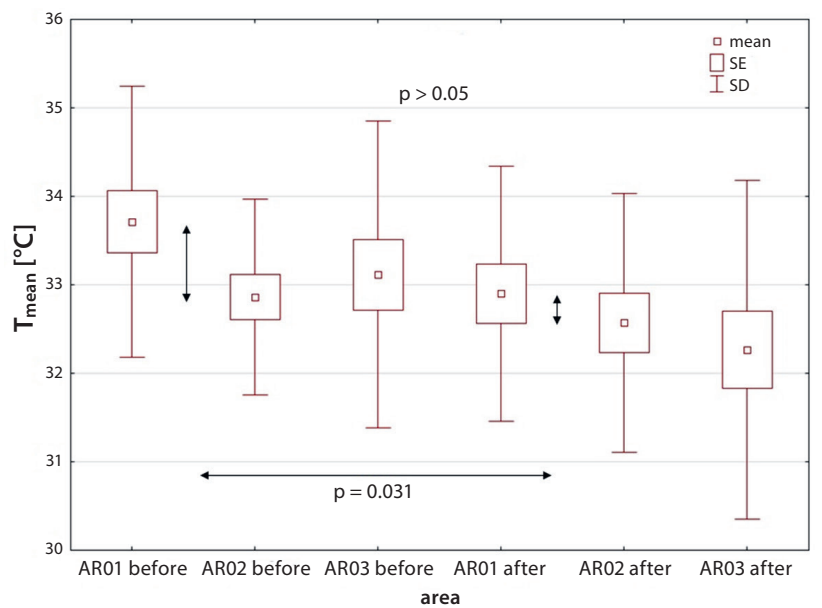

Fig. 7. Changes of $T_{\text {mean }}$ obtained from chosen areas for studied group of patients performed before and after hyperbaric oxygen therapy $(\mathrm{HBOT})^{14}$ SE - standard error; SD - standard deviation. 

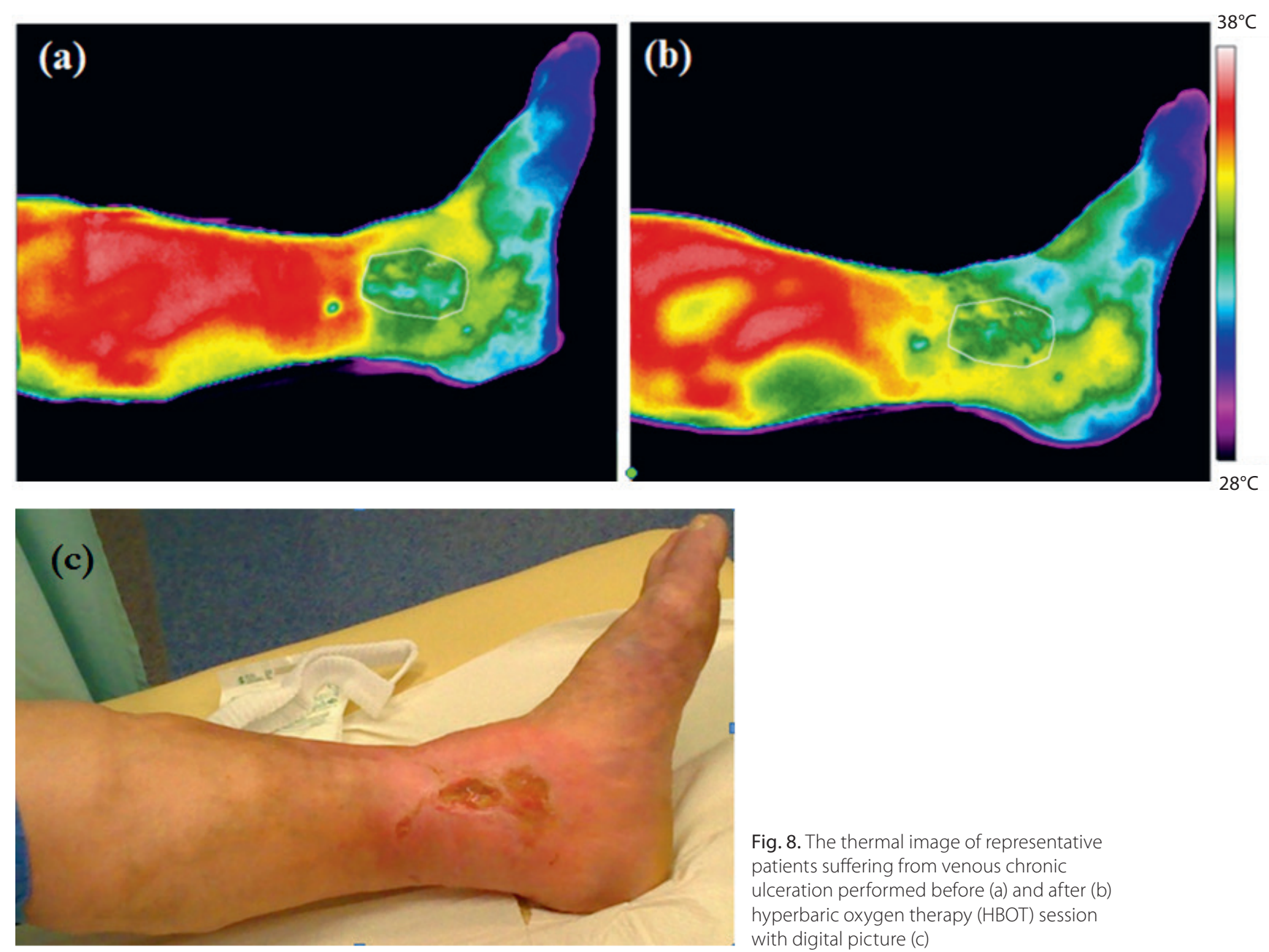

Fig. 8. The thermal image of representative patients suffering from venous chronic ulceration performed before (a) and after (b) hyperbaric oxygen therapy (HBOT) session with digital picture (c)

\section{Discussion}

Considering the fact that ulcers resulting from the diabetic foot syndrome and lower limb venous ulcers are a significant health problem in contemporary society, attempts were made to perform an objective assessment of the efficacy of the HBOT in chronic wounds treatment. ${ }^{10}$ The positive influence of HBOT observed in our study included a reduced wound perimeter as well as greater healing progress, allowing for earlier wound closure by intermediate thickness skin grafts. To obtain objective data on the wound healing process, digital planimetry (computer measurement) and thermal imaging were used. The monitoring of wound healing progress by planimetry influenced the patient's attitude towards the treatment process and increased the patient's involvement in the therapy. On the other hand, thermal imaging provides important information about inflammatory state changes and increased or decreased metabolism processes occurring in the ulcer area. This is connected with problems in blood microcirculation, which are a significant problem in pharmacotherapy.

The measurement of wounds using computerized digital planimetry allowed the physicians to objectively assess the effectiveness of the treatment, had a direct influence on the decisions pertaining to the selection of optimal wound treatment methods and reduced the costs of therapy. The clinical effects of the treatment could be assessed on the basis of objective results of planimetric measurements as well as a thermal analysis, which was reported in literature. ${ }^{6,7,14-18}$ In our study, the planimetric measurements showed that the surface area and the perimeter of the wound had decreased after the completion of HBOT in both groups of patients. Rogers et al. compared the accuracy of the wound measurement according to its shape and the method used (manual measurement using a rope and a measurement using digital planimetry). The results of their study also described the risk of error in the assessment of the surface area of the wound. ${ }^{19}$ Sieron et al. described a method for objective ulcer healing assessment using digital computer planimetry, in which the results of measurements allowed for a more accurate assessment of the wound healing process. ${ }^{20}$ The authors of the study described the frequent measurement errors using other techniques, i.e., a ruler or transparent film placed over the wound, which result from a curved surface of the skin (e.g., on the limb), or problems with proper identification of the wound edges . Moreover, the authors emphasize low accuracy of measurements and doubt 
the repeatability of results. Errors in the wound surface area assessments varied in range from $0.72 \mathrm{~cm}^{2}$ to even $10 \mathrm{~cm}^{2}$, and they could reach as much as $33 \%$ if a ruler was used. ${ }^{20}$ Goldman et al. described that the repeatability index for assessing the surface area and perimeter of the wound using computer planimetry was nearly 93\%, which allowed for using this method effectively in a clinical assessment of wound healing. In the same study, they emphasized that linear measurements based on the 2 longest dimensions of the wounds, depending on their shape, resulted in overestimation of their surface areas by as much as $25 \% .{ }^{21}$ In the presented study, all measurements (the patient's position and the setting of the distance between the lens and the wound surface) were performed using repeatable conditions. Samad et al. stated that these conditions play the key role in determining margins of the wound and in their digital assessment. ${ }^{22}$ Wounds with a large surface area, which affect the lower leg circumferentially, continue to be a problem, as photographs of wounds can be taken only perpendicularly. Hence, patients with circumferential ulcers were excluded from the research, as it was not possible to perform accurate measurements. Both domestic and foreign research on the impact of HBOT on chronic wound treatment indicates its beneficial influence. ${ }^{23,24}$ A systematic overview of research revealed a statistically significant difference in the reduction of the risk of large amputations and increased chances of wound healing. ${ }^{24-26}$ In the presented study, a reduced perimeter and surface area of the wounds was observed; therefore, it can be said that the therapy was successful. As HBOT is known to be an effective tool, it would be reasonable to focus on this form of therapy. If it is combined with other well-established wound management methods, such as new dressing types, negative pressure wound therapy, etc., the rate of successfully cured patients would likely increase and a reduced number of amputations could be expected.

Moreover, taking into consideration thermal imaging as a non-invasive technique that allows to see metabolic tissue activity, it was reported in literature that the skin temperature changes due to the HBOT, which can be clearly seen in Fig. 6. ${ }^{15-17}$ According to thermal imaging performed before HBOT, the increased temperature is observed around the ulceration. It can be recognized as an inflammatory state and increased metabolism processes occurring in this area. It may also be associated with the wrong functioning of microcirculation due to capillary circulation malfunction. The thermal map seems to be changed after HBOT and the temperature generally decreases in the regions of interest. This might be the result of improved thermoregulation resulting from improved microcirculation due to the start of angiogenesis. The temperature drop is observed mainly in the area above the wound. Such observation may be useful in evaluation of treatment effects as a symptom of healing process. It might be the result of a decrease in swelling observed above the wound and of improvement in blood microcirculation, which can play a main role in improving thermoregulation. It may have therapeutic meaning, because it leads to better oxygen transport to further parts of the tibia and increase oxygen concentration in the tissues, which was disturbed when the swelling occurred. These processes may improve the blood supply, start neoangiogenesis and, therefore, neovascularization, which is an indication of wound healing.

It seems that the temperature changes corresponding with planimetry measurements can be connected with patient's state of health (structurally in the case of planimetry and metabolically in the case of thermal imaging), which seems to be very useful in prognosis and qualification for further therapies.

\section{Conclusions}

The performed thermal imaging and planimetry studies showed a decrease in the wound area due to HBOT in patients with ulcers, chronic venous insufficiency and diabetic foot syndrome; HBOT has been proven to have a beneficial influence on the healing process. It seems that joint use of thermal imaging and planimetry may provide additional information about the wound structure and metabolism activity in the wound vicinity, and lead to increased accuracy of diagnosis as well as better therapy effects.

On the other hand, digital computer planimetry, as an objective assessment method of the healing process of selected chronic wounds before and after HBOT, allows for the monitoring of the healing process and makes it possible to plan further therapeutic actions.

\section{References}

1. Fife $\mathrm{CE}$, Hopf H. Hyperbaric oxygen: Its mechanisms and efficacy. Plast Reconstr Surg. 2011;127(Suppl 1):131-141.

2. Brown ML, Tang W, Patel A, Baumhauer JF. Partial foot amputation in patients with diabetic foot ulcers. Foot Ankle Int. 2012;33(9):707-716.

3. Jones V, Grey JE, Harding KG. ABC of wound healing. BMJ. 2006; 332(7544):777-780.

4. Oien RF, Håkansson MD, Hansen BU, Bjellerup MD. Measuring the size of ulcers by planimetry: A useful method in the clinical setting. J Wound Care. 2002;11(5):165-168.

5. Woodbury MG, Houghton PE, Campbell KE, Keast DH. Pressure ulcer assessment instruments: A critical appraisal. Ostomy Wound Manage. 1999;45(5):42-55.

6. Shah A, Wollak C, Shah JB. Wound measurement techniques: Comparing the use of ruler method, 2D imaging and 3D scanner. J Am Coll Clin Wound Spec. 2015;5(3):52-57.

7. Kawecki M, Knefel G, Wróblewski P. Przydatność planimetrii komputerowej w ocenie wyników leczenia ran przewlekłych. Pol Przegl Chir. 2011;83(1);1.

8. Foltynski P, Ladzynski P, Ciechanowska A, Migalska-Musial K, Judzewicz G, Sabalinska S. Wound area measurement with digital planimetry: Improved accuracy and precision with calibration based on 2 rulers. PLoS One. 2015;7;10(8):e0134622.

9. Bauer J, Hurnik P, Zdziarski J, et al. Thermovison and its application in medicine. Acta Bio-Optica et Informatica Medica Inżynieria Biomedyczna. 1997;3(2-4):121-131.

10. Jawień A, Szewczyk MT, Kaszuba A, et al. Guidelines for the management of chronic venous leg ulceration. Recommendations of a multidisciplinary expert group [in Polish]. Leczenie Ran. 2011;8(3):59-80. 
11. Szewczyk MT, Mościcka P, Cierzniakowska K, Jawień A. Opieka nad raną przewlekłą. Zakażenia. 2010;10(5):70-76.

12. Ring EFJ, Ammer K. The technique of infrared imaging in medicine. Thermology International. 2000;10(1):7-14.

13. Bauer J, Dereń E. Standardization of infrared thermal imaging in medicine and physiotherapy. Acta Bio-Optica et Informatica Medica Inżynieria Biomedyczna. 2014;20(1):11-20.

14. Liszka G, Englisz B, Knefel G, et al. Evaluation of hyperbaric oxygen therapy effects in ulceration of cruras studied by thermal imaging and planimetry: Preliminary results. Thermology International. Vol 26 (2016), Supplement: 16-18.

15. Cholewka A, Knefel G, Stanek A, et al. Thermal imaging and TC oximetry measurements of hyperbaric oxygen therapy (HBO) effects on trophic ulceration of the crura. J Therm Anal Calorim. 2012;108(1):25-31.

16. Cholewka A, Stanek A, Sieroń A, Drzazga Z. Thermovision in physical medicine. In: Podbielski, H, Skrzek A, eds. Biomedical Application of Thermovision. Wrocław, Poland: OWPW; 2014:37-48.

17. Cholewka A, Drzazga Z, Sieron A, Stanek A, Knefel G, Kawecki M, Nowak M. Some Applications of Thermal Imaging in Medicine. In Drzazga Z, Slosarek K. eds, Some Aspects Of Medical Physics - In Vivo And In Vitro Studies (Monographs of Polish Journal of Environmental Studies) 1: 51-58, 2010.

18. Jørgensen LB, Sørensen JA, Jemec GB, Yderstraede KB. Methods to assess area and volume of wounds: A systematic review. Int Wound J. 2015;13(4):540-553.
19. Rogers LC, Bevilacqua NJ, Armstrong DA, Andros G. Digital planimetry results in more accurate wound measurements: A comparison to standard ruler measurements. J Diabetes Sci Technol. 2010;(4)4: 799-802.

20. Sieroń A, Nowak M, Knefel G, Szymańska B, Kawecki M. Obiektywizacja gojenia ran przewlekłych aparatem IRIS S firmy Medicom. Leczenie Ran. 2007;4(4):141-144.

21. Goldman RJ, Salcido R. More than one way to measure a wound: An overview of tools and techniques. Adv Skin Wound Care. 2002; 15(5):236-245.

22. Samad A, Hayes S, French L, Dodds S. Digital imaging versus conventional contact tracing for the objective measurement of venous leg ulcers. J Wound Care. 2002;11(4):137-140.

23. Kranke P, Bennett MH, Martyn-St James M, Schnabel A, Debus SE, Weibel S. Hyperbaric oxygen therapy for chronic wounds. Cochrane Database Syst Rev. 2015;6:CD004123.

24. Huang ET, Mansouri J, Murad MH, et al; UHMS CPG Oversight Committee. A clinical practice guideline for the use of hyperbaric oxygen therapy in the treatment of diabetic foot ulcers. Undersea Hyperb Med. 2015;42(3):205-247.

25. Löndahl M. Hyperbaric oxygen therapy as treatment of diabetic foot ulcers. Diabetes Metab Res Rev. 2012;28(Suppl 1):78-84.

26. Schreml S, Szeimies RM, Prantl L, Landthaler M, Babilas P. Wound healing in the $21^{\text {st }}$ century. J Am Acad Dermatol. 2010;63(5):866-881. 